H. Kastner, U. Einhorn-Stoll, S. Drusch

\title{
Structure formation in sugar containing pectin gels - Influence of gel composition and cooling rate on the gelation of non- amidated and amidated low-methoxylated pectin
}

Journal article | Accepted manuscript (Postprint)

This version is available at https://doi.org/10.14279/depositonce-9769

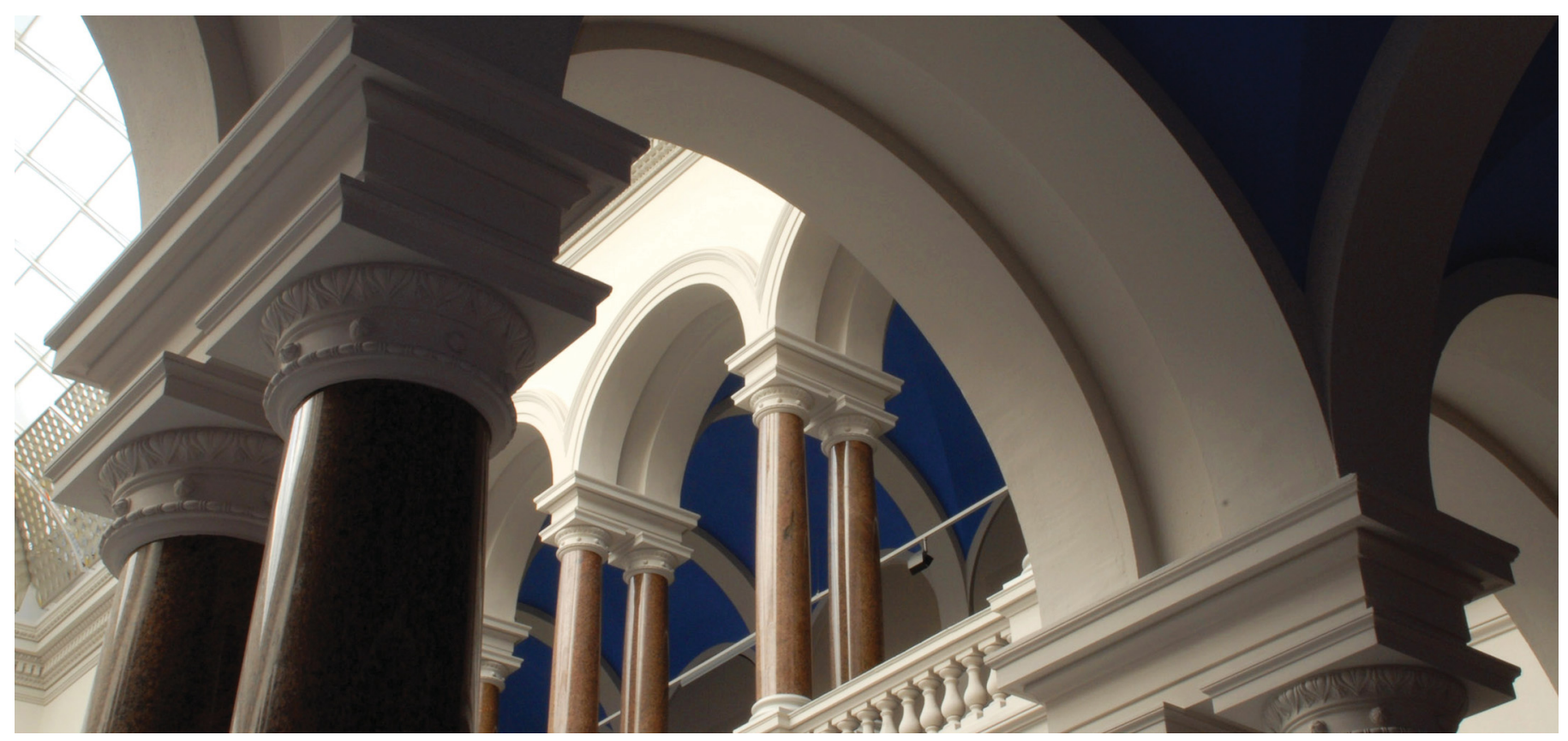

Kastner, H., Einhorn-Stoll, U., \& Drusch, S. (2017). Structure formation in sugar containing pectin gels Influence of gel composition and cooling rate on the gelation of non-amidated and amidated lowmethoxylated pectin. Food Hydrocolloids, 73, 13-20. https://doi.org/10.1016/j.foodhyd.2017.06.023 


\title{
Structure formation in sugar containing pectin gels - Influence of gel composition and cooling rate on the gelation of non-amidated and amidated low-methoxylated pectin
}

\author{
H. Kastner*, U. Einhorn-Stoll, S. Drusch
}

Technische Universität Berlin, Food Technology and Food Material Science, Königin-Luise-Strasse 22, D-14195 Berlin, Germany

*Corresponding author.; e-mail-address: h.kastner@tu-berlin.de

\section{Abstract}

Gel structure formation and gel properties of low-methoxyl pectin (LMP) and low-methoxyl amidated pectin (LMAP) with similar degree of methoxylation have been investigated by oscillatory rheological measurements. The gelling process was examined in a sugar-acid environment matching the conditions in jams and jellies. Factors studied included cooling rate, calcium content and $\mathrm{pH}$. Parameters derived from the rheological measurements comprised the gel point, structuring velocity, initial and critical structuring temperature, average structuring developing rate and loss factor ( $\left.\tan \delta_{\text {end }}\right)$.

The influence of the cooling rate on the gelling process of LMP was moderate and the influence on the final gel properties was significant, $\tan \delta_{\text {end }}$ decreased with increasing cooling rate. The calcium content significantly affected the structuring process of LMAP and the final gel properties. At high calcium content, the gelling process started at a higher temperature but the resulting gels were less strong. The $\mathrm{pH}$ had a significant but partly opposite effect on the gelation of LMP as well as LMAP. The differences in gelation behavior between LMP and LMAP can be explained by the lower number of available blocks of free carboxyl groups in LMAP as well as by the formation of additional hydrogen bonds through the amide groups. 


\section{Introduction}

Pectin is a polysaccharide and extracted from plant cell walls. It is used in the food industry for its gelling, thickening, stabilizing, and emulsifying properties. Variations in pectin structure enable this broad range of commercial applications. Depending on the degree of methoxylated carboxyl groups (degree of methoxylation, DM) pectins are traditionally classified as high-methoxylated pectins (HMP) with DM > 50\% and low-methoxylated pectins (LMP) with $\mathrm{DM}<50 \%$. Chemical deesterification of HMP in presence of ammonium ions results in low-methoxylated amidated pectin (LMAP).

For understanding of the gelling process of pectin it is helpful to review the types of junction zones in pectin gels. A limited number of hydrophobic interactions may be formed between the methyl ester groups immediately at the beginning of the cooling process and induce the gelation (Oakenfull $\&$ Scott, 1984). These interactions have a rather low energy, a limited working range of about $2 \mathrm{~nm}$ (Walstra, 2002, Chapter 3) and become weaker with decreasing temperature. Upon further cooling, at lower temperatures hydrophilic interactions between undissociated carboxyl groups of the galacturonic acid and/or hydroxyl groups of carboxyl, hydroxyl or amide groups can develop via hydrogen bonds (Oakenfull \& Fenwick, 1977; Oakenfull \& Scott, 1984). These bonds are also of low energy and with $0.2 \mathrm{~nm}$ their working range is even smaller than that of the hydrophobic interactions. That means that the pectin molecules have to come in close contact in order to form a gel network. This can be achieved by a high soluble solid concentration (>50\%) since the resulting reduced water activity allows the approach of pectin chains (Evageliou, Richardson, \& Morris, 2000; Kastner et al., 2014; Thakur, Singh, Handa, \& Rao, 1997). The influence of the hydrogen bonds gains more importance upon temperature reduction and supports inter-chain association during network formation. These two types of junction zone formation occur during gelation in all types of pectin and are typical for a cold-set gelation (Burey, Bhandari, Howes, \& Gidley, 2008). However, gelation of LMP is governed by ionic interactions between dissociated carboxyl groups, typically via calcium ion bridges (Thibault \& Ralet, 2003) in an ionotropic gelation (Burey et al., 2008). Calcium bridges represent a third type of junction zone formation and start to form immediately after gel preparation. They are much stronger than hydrophobic and hydrogen bonds and with about $20 \mathrm{~nm}$ their working range is rather long (Walstra, 2002, Chapter 3). Pectin gels with combined or dominating ionic junction zones require less soluble solids than HMP gels based on hydrophobic or hydrogen bonds, and can be formed also in sugar-free systems. The ionotropic gelation can take place in pectin solutions without heating (Ström \& Williams, 2003; Vincent \& Williams, 2009) and can be performed also as isothermal titration at room temperature (Fang et al., 2008). It seems to be possible, however, that ionic interactions formed at higher temperature tend to be initially not stable but their stability will increase during cooling (Cárdenas, Goycoolea, \& Rinaudo, 2008; Garnier, Axelos, \& Thibault, 1993). In LMAP, junction zones are additionally stabilized by hydrogen 
bonds involving the amide group (Alonso-Mougán, Meijide, Jover, Rodríguez-Núñez, \& VázquezTato, 2002; Black \& Smit, 1972; Löfgren, Guillotin, \& Hermansson, 2006).

Structure formation and properties of pectin gels strongly depend on intrinsic and extrinsic factors (Endress \& Christensen, 2009; Rolin, Chrestensen, Hansen, Staunstrup, \& Sørensen, 2009; Yapo \& Gnakri, 2015). Intrinsic factors affecting a system are those related to the composition, e.g. type of pectin and concentration, agent used for $\mathrm{pH}$ adjustment, presence of divalent cations or co-solutes like sugar. Important extrinsic (technological) factors are e.g. heating and cooling conditions. The influence of calcium ions depends on the stoichiometric ratio between calcium ions and the dissociated free carboxyl groups. This ratio is calculated as $\mathrm{R}=2\left[\mathrm{Ca}^{2+}\right] /[\mathrm{COO}]$ (Axelos \& Kolb, 1990; Capel, Nicolai, Durand, Boulenguer, \& Langendorff, 2006; Cárdenas et al., 2008; Garnier et al., 1993; Ström et al., 2007). A theoretical saturation threshold of the R exists at which every calcium ion in the gel is bound to two dissociated carboxyl group. This threshold is affected on one hand by the degree of dissociation of the carboxyl groups and, thus, by the $\mathrm{pH}$ in the gel system. The $\mathrm{pK}_{\mathrm{a}}$ of pectin is about 3.5 (Ralet, Dronnet, Buchholt, \& Thibault, 2001), at this $\mathrm{pH} 50 \%$ of the carboxyl groups are dissociated. On the other hand, the binding of calcium to pectin chains also depends on the distribution of these groups (block-wise or random). lonic interactions require a certain number (blocks) of about 6 to 14 subsequent dissociated carboxyl groups (Liners, Thibault, \& Cutsem, 1992; Luzio \& Cameron, 2008; Powell, Morris, Gidley, \& Rees, 1982) in order to form junction zones named as "egg-boxes". Vincent and Williams (2009) therefore suggested a modified

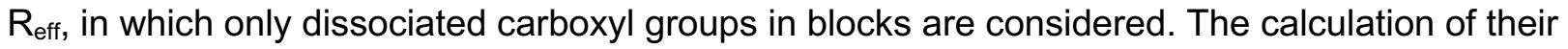
exact number requires, however, detailed knowledge of the pectin molecular structure. Single randomly distributed dissociated carboxyl groups may also interact with calcium ions. In case they are oriented to the outside of the egg-boxes, they could form larger dimer aggregates and even an extended network (Braccini \& Pérez, 2001; Fraeye et al., 2009, 2010). Moreover, excess calcium ions may be located in the gap between galacturonic acid molecules and interact with other C-atoms than C6 (Siew, Williams, \& Young, 2005), they might course a certain electrostatic repulsion. The number of rather unspecific or random calcium crosslinks will increase with increasing calcium ion content. The degree of methoxylation and the distribution of the carboxyl groups in a more random or more block-wise way can influence the gelling process especially with respect to the ionotropic gelation (Fraeye et al., 2009; Ngouémazong et al., 2012). According to Fraye et al. $(2009,2010)$ pectin with a dominating block-wise distribution of the dissociated carboxyl groups is able to gel at a lower calcium concentration $(R)$ than pectin with a more random distribution of free carboxyl groups. At higher calcium content $(R>1)$ pectin gels were found to become more cross-linked and elastic and a plateau of the storage modulus ( $G$ ') was reached only at very high calcium contents with $\mathrm{R}$ up to 5.0. Additional crosslinks might result from random interactions of calcium ions with single carboxyl groups as described above. When the calcium 
content becomes too high, precipitation and/or syneresis can occur and the gel strength may be reduced (Fraeye et al., 2010; Grosso \& Rao, 1998). Gels prepared from amidated pectins were found to be less sensitive to syneresis (Thakur et al., 1997; Thibault \& Ralet, 2003) than those of non-amidated pectins.

The complex gelling process and gel properties of pectin systems as well as the influence of different intrinsic and extrinsic factors on the gelation have been successfully examined by a variety of methods including a wide range of rheology-based methods. In the majority of studies, however, only one or two intrinsic factors have been varied, like e.g. pectin concentration, co-solutes, ion concentration, type of ions or acid and alkaline media to adjust the $\mathrm{pH}$ (Evageliou et al., 2000; Fraeye et al., 2010; Gigli, Garnier, \& Piazza, 2009; Guillotin, Van Kampen, Boulenguer, Schols, \& Voragen, 2006; Löfgren et al., 2006; Löfgren \& Hermansson, 2007; Lopes da Silva \& Gonçalves, 1994; Rao \& Cooley, 1993; Sousa, Nielsen, Armagan, Larsen, \& Sørensen, 2015; Ström et al., 2007; Tsoga, Richardson, \& Morris, 2004). As a consequence, the results of some of these studies are hardly comparable because of differences in the intrinsic factors of the model system as well as extrinsic factors in the experimental setup, methodology or measuring equipment. In addition, often only one parameter, the classical gel point (GP) defined as crossover of storage modulus G' and loss modulus G" at a certain frequency, was reported (Gigli et al., 2009; Holst, Kjøniksen, Bu, Sande, \& Nyström, 2006; Iglesias \& Lozano, 2004). In recent years, the rheological characterization of a gelling process was significantly improved by using new parameters like the initial structuring temperature (IST), defined as the temperature at which the first derivation of G' as a function of time $\left(d G^{\prime} / d t\right)$ differed from zero for the first time, and the critical structuring temperature (CST) as the extrapolated temperature of the first strong increase of dG'/dt (Kastner et al., 2014; Kastner, Einhorn-Stoll, \& Senge, 2012a, 2012b; Einhorn-Stoll, Kastner, \& Senge, 2012; Einhorn-Stoll, Kastner, Hecht, Zimathies, \& Drusch, 2015). This method allows the evaluation of the gelling kinetics and the final gel properties and, thus, gives information about systems without clear gel point. These new parameters are now generally accepted and have been used by several other groups (Garrido, Lozano, \& Genovese, 2015; Sousa et al., 2015; Wang, Hua, Yang, Kang, \& Zhang, 2014).

For these reasons, in the last years the overall aim of our group was the investigation of the pectin gelling process and the final gel properties in a broad study, covering all major factors such as pectin type, content of calcium ions, $\mathrm{pH}$ and cooling rate. Several results have already been achieved and published and complementary examinations are the subject of the present study. The kinetics of structure formation of HMP gels, a typical cold-set gelation, as well as the properties of the final gels were investigated before at varying cooling rates and $\mathrm{pH}$ (Kastner et al., 2014). A high cooling rate promoted early structure formation and resulted in a less elastic gel compared to a low cooling rate. Varying the $\mathrm{pH}$ by differences in the acid concentration showed that an optimum range 
for the structure formation as well as for the final gel properties at intermediate acid concentration exists. In the present study the influence of the cooling rate on the gelation of LMP will be investigated because it is assumed that here the temperature-independent ionic interactions (ionotropic gelation) will dominate the gelation process and reduce the influence of the cooling rate (cold-set gelation). Moreover, the influence of $\mathrm{pH}$ on the gelation of LMP and LMAP will be examined, because it is assumed that a reduced number of dissociated carboxyl groups will considerably alter the gelling kinetics. On the one hand, a reduced number of dissociated carboxyl groups limits the ionic junction zones but on the other hand it supports the formation of hydrogen bonds. The impact of the calcium concentration on LMP gelation was studied already in nonamidated LMP gels (Kastner et al., 2012b). It was found that high calcium content caused gelling at higher temperature, a more rapid process and resulted in more elastic and also partly brittle gels. The present study will complete this research complex by analyzing the impact of the calcium concentration also on LMAP. Differences are expected because in LMAP the number of available blocks of free carboxyl groups at a similar DM is lower than in LMP and the role of hydrogen bonds is more pronounced because of the amide groups in the LMAP. 


\section{Materials and methods}

\subsection{Materials}

Two commercially available citrus pectins were used in the present study. The low-methoxylated pectin with DM 30\% and the low-methoxyl amidated pectin with DM 32\% and DA 19\% have already been characterized in previous studies (Einhorn-Stoll et al., 2015; Einhorn-Stoll, Prinz, \& Drusch, 2014; Einhorn-Stoll, Kastner, \& Drusch, 2014; Kastner et al., 2012b). Citric acid, trisodium citrate dihydrate and calcium chloride dihydrate were of analytical grade (Sigma-Aldrich Chemie $\mathrm{GmbH}$, Taufkirchen, Germany). Sucrose was food grade and purchased locally.

\subsection{Methods}

\subsubsection{Examination of the structure formation process and final gel structure}

The gelation of LMP and LMAP was investigated in a sugar-acid environment. The standard gel composition and preparation for LMP gels was the same as in Kastner et al. (2012b): A solution of $637.5 \mathrm{~g}$ demineralized water, $264 \mathrm{~g}$ sucrose, $7.5 \mathrm{~mL} 54.3 \% \mathrm{w} / \mathrm{v}$ citric acid solution, $15 \mathrm{~mL} 6 \% \mathrm{w} / \mathrm{v}$ sodium citrate solution, $37.5 \mathrm{~mL} 2.205 \% \mathrm{w} / \mathrm{v}$ calcium chloride dihydrate solution and $6 \mathrm{~g}$ pectin were reduced by boiling to a total mass of $900 \mathrm{~g}$. This standard gel composition was varied depending on the aim of the specific investigation, but the total content of solids was kept constant for all systems at $30 \mathrm{wt} . \%$. All gels were prepared at least in triplicate.

In order to investigate the gelling process of LMP gels, three different aspects were considered. (I) For the variation of the cooling conditions, standard LMP gels were cooled with different rates of $0.25,0.50,0.75,1.00,1.50$ and $2.00 \mathrm{~K} / \mathrm{min}$, comparable to the recent investigation of HMP (Kastner et al., 2014). (II) The influence of calcium on the structuring process of LMAP was studied, under the same conditions like in the study of LMP (Kastner et al., 2012b). Different amounts of $2.205 \%$ $\mathrm{w} / \mathrm{v}$ calcium chloride dihydrate solution were added: $25 \mathrm{~mL}(4.2 \mathrm{mM} / \mathrm{kg}$ gel), $3 \mathrm{~mL}(5.2 \mathrm{mM} / \mathrm{kg}$ gel), $37.5 \mathrm{~mL}$ (6.2 mM/kg gel), $44 \mathrm{~mL}(7.3 \mathrm{mM} / \mathrm{kg}$ gel), and $50 \mathrm{~mL}(8.3 \mathrm{mM} / \mathrm{kg}$ gel). The resulting stoichiometric ratio between calcium and free carboxyl content $\mathrm{R}=2\left[\mathrm{Ca}^{2+}\right] /\left[\mathrm{COO}^{-}\right]$was $0.73 / 0.90 /$ 1.09 / 1.28 and 1.45, respectively. The regular amount of $\mathrm{CaCl}_{2}$ in the standard procedure was $37.5 \mathrm{~mL}(6.2 \mathrm{mM} / \mathrm{kg}$ gel, $\mathrm{R}=1.09)$; variations were made in both directions. (III) The $\mathrm{pH}$ influence was tested for both LMP types by adding different amounts of $54.3 \% \mathrm{w} / \mathrm{v}$ citric acid solution. For the LMP, the $\mathrm{pH}$ range was from 5.0 to 2.9 with the following volumes of citric acid solution: $1.5 \mathrm{~mL}$ (4.7 mM/kg gel), $3.5 \mathrm{~mL}$ (11.0 mM/kg gel), $5.5 \mathrm{~mL}(17.3 \mathrm{mM} / \mathrm{kg}$ gel), $7.5 \mathrm{~mL}(23.6 \mathrm{mM} / \mathrm{kg}$ gel), $9.5 \mathrm{~mL}(29.8 \mathrm{mM} / \mathrm{kg}$ gel), and $11.5 \mathrm{~mL}(36.1 \mathrm{mM} / \mathrm{kg}$ gel $)$. The regular amount of citric acid in the standard LMP gel was $7.5 \mathrm{~mL}(23.6 \mathrm{mM} / \mathrm{kg}$ gel); variations were made in both directions. The stoichiometric ratio of calcium ions in the LMP gels was $\mathrm{R}=0.7$. For the LMAP, the $\mathrm{pH}$ range was from 5.3 to 3.0 with the following added volumes of citric acid solution: $1.5 \mathrm{~mL}(4.7 \mathrm{mM} / \mathrm{kg}$ gel), 
$3.5 \mathrm{~mL}$ (11.0 mM/kg gel), $5.5 \mathrm{~mL}$ (17.3 mM/kg gel), $7.5 \mathrm{~mL}(23.6 \mathrm{mM} / \mathrm{kg}$ gel), and $9.5 \mathrm{~mL}$ (29.8 $\mathrm{mM} / \mathrm{kg}$ gel). The stoichiometric ratio of calcium ions was $\mathrm{R}=1.09$. The standard cooling rate for all gels of both pectins was held constant at $1 \mathrm{~K} / \mathrm{min}$.

The viscoelastic behavior of the samples during cooling was characterized by small deformation oscillation measurements using a rheometer Physica MCR 301 (Anton Paar, Ostfildern, Germany) equipped with a profiled rotational cylinder CC27/P1 (diameter $26.66 \mathrm{~mm}$, length $40.01 \mathrm{~mm}$ ) and Peltier cylinder temperature system TEZ 150P. Samples were transferred onto the pre-heated rheometer $\left(100{ }^{\circ} \mathrm{C}\right)$ and cooled to $10^{\circ} \mathrm{C}$ by a standard cooling rate of $1 \mathrm{~K} / \mathrm{min}$ or in variation from 0.25 to $2 \mathrm{~K} / \mathrm{min}$, respectively. The dynamic rheological parameters, storage modulus (G') and loss modulus (G'), were recorded during cooling at constant frequency of $1 \mathrm{~Hz}$ and strain of $10^{-3}$ as previously described (Kastner et al., 2012b).

The final structure of the gels was characterized by the loss factor at $10^{\circ} \mathrm{C}$ ( $\tan \delta_{\text {end }}$ ). The $\mathrm{pH}$ was determined in the cooled gels using a Lab850 pH-meter (Schott Instruments) and a special penetration electrode (BlueLine $14 \mathrm{pH}$, Schott Instruments).

\subsubsection{Determination of structuring temperatures and average structure developing rate}

Different parameters were calculated from the measurements of the temperature sweeps in order to describe the gelling process: The classical gel point (GP) was defined as cross-over of G' and G" with $\tan \delta=G^{\prime \prime} / G^{\prime}=1$. Initial structuring temperature (IST) and critical structuring temperature (CST) were determined from the structuring velocity $(\mathrm{dG} / \mathrm{dt})$, the first derivation of $\mathrm{G}^{\prime}$ as function of time using OriginPro9.1 software (OriginLab Corp., Northampton, USA) (Kastner et al., 2014, 2012a, 2012b). The structuring velocity curves were mean curves of at least 3 separate measurements. For the overall structuring process the average structure developing rate $\left(\mathrm{SDR}_{\mathrm{a}}\right)$ was calculated (Kastner et al., 2012b):

$S D R_{a}=\frac{G_{\text {end }}^{\prime}-G_{\text {IST }}^{\prime}}{t_{\text {end }}-t_{I S T}}$

\subsubsection{Statistical analysis}

Analysis of variance with a Kruskal-Wallis test (KWANOVA) was carried out in order to examine the significance of effects of cooling rate, calcium concentration $(\mathrm{R})$ and acid concentration $(\mathrm{pH})$ on structuring temperatures (IST, CST, GP), $\tan \delta_{\text {end }}$ and $\mathrm{SDR}_{\mathrm{a}}$. All tests were performed with OriginPro9.1 software (OriginLab Corp., Northampton, USA) at a significance level of 0.05 (95\% confidence interval). 


\section{Results and discussion}

\subsection{Effect of the cooling rate on structure formation and gel properties for LMP}

Standard LMP gels were cooled at different cooling rate ranging from 0.25 to $2.00 \mathrm{~K} / \mathrm{min}$. It was assumed that the formation of junction zones during gelation of LMP was less dependent of temperature than in case of HMP gelation (Kastner et al., 2014).

The structuring velocity curve ( $\left.d G^{\prime} / d t\right)$ of the LMP gels showed a systematic increase with increasing cooling rate (Fig. 1). In case of the lowest cooling rate of $0.25 \mathrm{~K} / \mathrm{min}$ it seems that the energy content of the system was rather high during the long time keeping at high temperature and the small number of hydrophobic interactions (at the low DM) was not sufficient for a substantial gel formation. The formation of hydrogen bonds was delayed, too. The distance between pectin molecules was large and the ionic bonds were not completely stable, yet (Cárdenas et al., 2008; Garnier et al., 1993). Moreover, calcium ions might be delocalized between the pectin molecules instead of binding closely in bridges and forming a strong gel. The latter effect might be comparable to the counter ion condensation as described by Siew, Williams, and Young (2005). It can be, in general, assumed that a fast cooling (e.g. $2 \mathrm{~K} / \mathrm{min}$ ) supports early formation of calcium bridges, stabilized by the more rapid formation of hydrogen bonds. The IST varied between 59.5 and $65.8^{\circ} \mathrm{C}$ (Table 1), the CST differed between 43.4 and $53.6^{\circ} \mathrm{C}$. The GP significantly differed and was between IST and CST for all cooling rates (Table 1). The SDR $\mathrm{B}_{\mathrm{a}}$ of the non-amidated LMP gels was generally low (Table 1). It slightly, but significantly increased with increasing cooling rate because the strong reduction of cooling time dominated the moderate increase of G'.

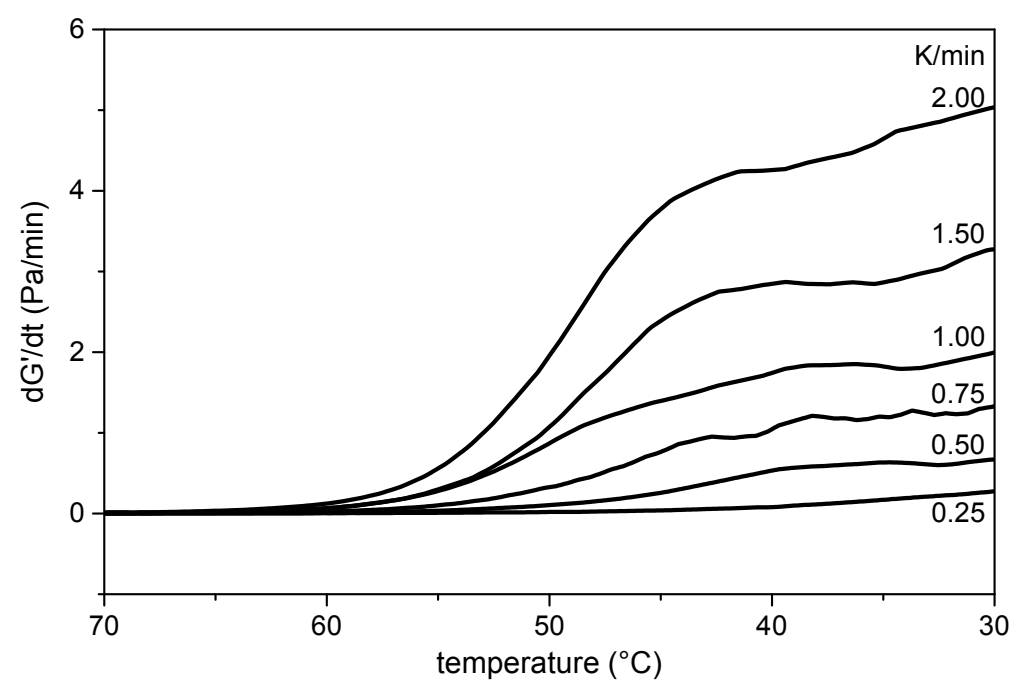

Fig. 1 Influence of the cooling rate (K/min) of standard LMP gel on the structuring velocity (dG'/dt). 
Table 1 Gelling parameters of standard LMP gel in dependence on the cooling rate. IST = initial structuring temperature, CST = critical structuring temperature, $G P=$ gel point, $\tan \delta_{\text {end }}=$ loss factor as determined after the end of the gelation, $S D R_{a}=$ average structure developing rate. $\mathrm{P}$ indicates significant differences: * for $\mathrm{P}<0.05,{ }^{* *}$ for $\mathrm{P}<0.01$ and ${ }^{* * *}$ for $\mathrm{P}<0.001$.

\begin{tabular}{cccccc}
\hline cooling rate $(\mathrm{K} / \mathrm{min})$ & $\left.\mathrm{IST}^{\circ}{ }^{\circ} \mathrm{C}\right)$ & $\mathbf{C S T}\left({ }^{\circ} \mathbf{C}\right)$ & $\mathbf{G P}\left({ }^{\circ} \mathrm{C}\right)$ & $\tan _{\text {end }}$ & SDR $_{\mathbf{a}}(\mathrm{Pa} / \mathbf{m i n})$ \\
\hline $\mathbf{0 . 2 5}$ & 59.5 & 43.4 & 56.6 & 0.167 & 0.2 \\
$\mathbf{0 . 5 0}$ & 58.1 & 49.5 & 52.8 & 0.142 & 0.6 \\
$\mathbf{0 . 7 5}$ & 61.2 & 51.3 & 60.8 & 0.135 & 1.1 \\
$\mathbf{1 . 0 0}$ & 65.8 & 53.1 & 57.2 & 0.131 & 1.6 \\
$\mathbf{1 . 5 0}$ & 62.4 & 54.1 & 57.9 & 0.128 & 2.9 \\
$\mathbf{2 . 0 0}$ & 61.3 & 53.6 & 53.6 & 0.127 & 3.9 \\
$P$ & $*$ & & $* *$ & $* *$ & $* *$ \\
\hline
\end{tabular}

The final LMP gels were relatively viscous (soft or liquid-like), their tan $\delta_{\text {end }}$ was rather high (Table 1). With increasing cooling rate, the $\tan \delta_{\text {end }}$ significantly but only slightly decreased, indicating that the final gel structure depended only weakly on the cooling rate. Thus, the influence of the cooling rate on junction zone length and the resulting final gel structure, as described for gels with hydrogen bonds such as gelatin (Ziegler \& Foegeding, 1990) and HMP gels (Kastner et al., 2014), could not be confirmed for the gelation of LMP via calcium bridges.

Comparing the influence of the cooling rate on the structuring behavior of LMP with that of HMP gels (Kastner et al., 2014), similarities as well as differences are found. The cooling rate in all pectin gels had a moderate influence on the structuring temperatures IST and CST but clearly increased the structuring velocity and affected the properties of the final gels. The cooling rate impact on LMP gels differed strongly from that of the HMP. The structuring temperature IST and CST of LMP gels were generally lower than those of HMP gels but also their structuring velocity was much lower. The most important difference with respect to the cooling rate is the difference in the final gel properties as indicated by $\tan \delta_{\text {end. }}$. Gels behaved completely opposite with increasing tan $\delta_{\text {end }}$ for HMP gels and decreasing $\tan \delta_{\text {end }}$ for LMP gels. The additional junction zones formed via calcium bridges in the LMP altogether reduced the influence of the cooling rate on the pectin gelation. These results confirm the postulated differences in the gelling mechanisms of HMP and LMP in sugar acid gel formulations caused by the additional occurrence of ionic interactions.

\subsection{Effect of calcium concentration on structure formation and gel properties for LMAP}

The amount of $\mathrm{CaCl}_{2}$ added to the gels was chosen based on the examination of the impact of calcium on gel formation of non-amidated LMP (Kastner et al., 2012b). The amount of $\mathrm{CaCl}_{2}$ in the standard gel was varied in both directions, so that a stoichiometric ratio between 0.72 and 1.45 were reached. The R-values in the LMAP gels were higher than those in the corresponding LMP 
gels at the same calcium content. Despite of a similar DM (about 30\%) of one LMAP and LMP, the presence of amidated carboxyl groups reduced the number of free dissociated carboxyl groups of LMAP and, thus, ionotropic gelation. Moreover, it was expected that even at similar R-values the results would differ because of the more pronounced role of hydrogen bonds of the amide groups in the cold-set gelation of LMAP.

Table 2 Gelling parameters of LMAP gel in dependence on the concentration of calcium. $R=$ stoichiometric ratio of calcium ions, IST = initial structuring temperature, CST = critical structuring temperature, GP = gel point, tan $\delta_{\text {end }}=$ loss factor as determined after the end of the gelation, $S D R_{a}=$ average structure developing rate. $\mathrm{P}$ indicates significant differences: * for $\mathrm{P}<0.05,{ }^{* *}$ for $\mathrm{P}<0.01$ and ${ }^{* * *}$ for $\mathrm{P}<0.001$.

\begin{tabular}{cccccc}
\hline $\mathbf{R}$ & $\mathbf{I S T}\left({ }^{\circ} \mathrm{C}\right)$ & $\mathbf{C S T}\left({ }^{\circ} \mathbf{C}\right)$ & $\mathbf{G P}\left({ }^{\circ} \mathrm{C}\right)$ & tan $_{\text {end }}$ & SDR $_{\mathrm{a}}(\mathrm{Pa} / \mathbf{m i n})$ \\
\hline $\mathbf{0 . 7 3}$ & 64.3 & 60.3 & 64.4 & 0.079 & 10.5 \\
$\mathbf{0 . 9 0}$ & 68.2 & 64.9 & 68.7 & 0.085 & 10.4 \\
$\mathbf{1 . 0 9}$ & 75.4 & 68.1 & 74.8 & 0.089 & 10.1 \\
$\mathbf{1 . 2 8}$ & 79.6 & 70.2 & 78.8 & 0.098 & 10.4 \\
$\mathbf{1 . 4 5}$ & 81.8 & 69.4 & - & 0.101 & 9.7 \\
$P$ & $* * *$ & $* * *$ & $*$ & $* * *$ & \\
\hline
\end{tabular}

The structuring velocity curves were similar in shape for all $R$ (data not shown), only the start of the gelling process differed. Below $60^{\circ} \mathrm{C}$, the structuring velocities increased parallel over a range of $30 \mathrm{~K}$ and achieved a similar level, followed by a subsequent non-linear structure development. The structuring temperatures IST and CST significantly increased with increasing calcium content (Table 2). This is in agreement with Lootens et al. (2003). The IST varied in a relatively broad range $(\Delta \mathrm{T}=17.5 \mathrm{~K})$ compared to the $\mathrm{CST}$, which varied in a smaller range $(\Delta \mathrm{T}=9.9 \mathrm{~K})$. The $\mathrm{GP}$ varied by 14.4 $\mathrm{K}$ between the samples, at $\mathrm{R}=1.45$ no GP was detectable. With increasing $\mathrm{R}$, the IST raised faster than the CST. It is assumed that a high calcium content in all gels induced a more rapid initial structure formation by immediately forming calcium bridges between blocks of dissociated free carboxyl groups (ionotropic gelation). The main structuring process as indicated by the CST, however, was not accelerated to the same extent. It seems likely that as a consequence of a surplus of calcium ions and the low share of dissociated carboxyl groups in blocks calcium ions did not only form bridges, but rather bound to one pectin chain and induced an electrostatic repulsion by their positive charge. The latter inhibits the gel stabilization by hydrogen bonds between undissociated carboxyl as well as amide groups (cold set-gelation), which have a much smaller working range and could not crosslink due to the distance between neighbored charged parts of the pectin molecules.

The SDR $\mathrm{a}$ was rather high and nearly constant, independent on $\mathrm{R}$ (Table 2). The loss factor ( $\tan \delta_{\text {end }}$ ) of the final LMAP gels was rather low in comparison to the corresponding standard LMP gel cooled at $1 \mathrm{~K} / \mathrm{min}$ (Table 1). The SDR slightly, but significantly increased at higher R (Table 2). 
The corresponding gels were more solid-like, as it was also described by (Lootens et al., 2003), and showed an increased brittleness. It must be assumed that at the highest calcium concentration local micro-gels as described in Kastner et al. (2014), have been formed rapidly before the start of the measurement, because no clear gel point could be determined for these gels.

The presented results of the effect of calcium ions on the structuring process of LMAP as well as those of the previous publication concerning the effect on non-amidated LMP (Kastner et al., 2012b) generally confirm the crucial role of calcium ions in the gelling process of low-methoxylated pectin. Comparing the influence of increasing calcium content on the gelation of non-amidated LMP with amidated LMP of a similar DM, however, considerable differences were found. LMAP required less calcium for starting the structuring process. An increase in calcium ions accelerated structure formation only to a certain extent, because the number of free carboxyl groups with block-wise distribution was smaller. After saturation of these groups with calcium ions, additional calcium may cause repulsion of pectin chains and delay the initial gelling step. The formation of hydrogen bonds of the amide groups, however, considerably contributed to the cold-set gelation at lower temperature and altered the kinetics of the structuring process as well as the properties of the final gels. It has to be kept in mind that the comparison is influenced by the different stoichiometric ratio. However, also a direct comparison of previously reported data on LMP gels (Kastner et al., 2012b) and the LMAP gels of the present study with similar $\mathrm{R}$ in the range of 0.7 to 0.9 confirmed the differences described above.

\subsection{Effect of acid content $(\mathrm{pH} \leq 4)$ on structure formation and gel properties for $L M P$ and LMAP}

Variation of the concentration of acid in LMP and LMAP gels results in $\mathrm{pH}$-values that varied around 3.5 , the $\mathrm{pK}_{\mathrm{a}}$ of pectin (Table 3). As outlined in 3.2 , addition of $6.25 \mathrm{mM} \mathrm{CaCl}_{2} / \mathrm{kg}$ gel meant a different stoichiometric ratio for the two pectin types. R amounted to 0.7 in the LMP gels and to 1.09 for the LMAP gels, respectively. Through variation of the $\mathrm{pH}$ it is possible to examine, how a reduction of dissociated carboxyl groups and pectin-calcium interactions on the one hand, and a possible increase of hydrogen bonds between undissociated carboxyl groups on the other hand affects gelation.

For LMP as well as LMAP, IST and CST decreased significantly with decreasing $\mathrm{pH}$. A clear GP was only found at $\mathrm{pH} \leq 3.1$ (Table 3 ). With decreasing $\mathrm{pH}$, the structuring temperatures decreased because of a reduction in the number of dissociated carboxyl groups with block-wise distribution. The latter are necessary for the rapid formation of ionic junction zones via calcium bridges at high temperature and decreased with increasing acid content. Thus, a reduced number of calcium bridges delayed the gelling process (Fig. 2a and b). Limited hydrophobic interactions (only about $30 \%$ of the carboxyl groups were methoxylated) were not sufficient for a quick effective gelation at 
temperatures $>50^{\circ} \mathrm{C}$. The structure formation at low $\mathrm{pH}$ is mainly due to the action of hydrogen bonds, but this process starts later at lower temperatures.

Table 3 Gelling parameters of LMP and LMAP gels in dependence on the concentration of acid. IST = initial structuring temperature, CST = critical structuring temperature, $G P=$ gel point, tan $\delta_{\text {end }}=$ loss factor as determined after the end of the gelation, $S D R_{a}=$ average structure developing rate. $\mathrm{P}$ indicates significant differences: * ${ }^{*} \mathrm{P}<0.05$, ${ }^{* *}$ for $\mathrm{P}<0.01$ and ${ }^{* * *}$ for $\mathrm{P}<0.001$.

\begin{tabular}{|c|c|c|c|c|c|c|c|c|c|c|c|c|}
\hline \multirow{2}{*}{$\begin{array}{l}\text { citric acid } \\
\text { (mM/kg gel) }\end{array}$} & \multicolumn{6}{|c|}{ LMP } & \multicolumn{6}{|c|}{ LMAP } \\
\hline & $\mathrm{pH}$ & $\begin{array}{l}\text { IST } \\
\left({ }^{\circ} \mathrm{C}\right)\end{array}$ & $\begin{array}{l}\text { CST } \\
\left({ }^{\circ} \mathrm{C}\right)\end{array}$ & $\begin{array}{l}\text { GP } \\
\left({ }^{\circ} \mathrm{C}\right)\end{array}$ & $\tan \delta_{e n d}$ & $\begin{array}{c}\text { SDR }_{a} \\
\text { (Pa/min) }\end{array}$ & pH & $\begin{array}{l}\text { IST } \\
\left({ }^{\circ} \mathrm{C}\right)\end{array}$ & $\begin{array}{l}\text { CST } \\
\left({ }^{\circ} \mathrm{C}\right)\end{array}$ & $\begin{array}{l}\text { GP } \\
\left({ }^{\circ} \mathrm{C}\right)\end{array}$ & $\tan \delta_{e n d}$ & $\begin{array}{c}\text { SDR }_{\mathrm{a}} \\
\text { (Pa/min) }\end{array}$ \\
\hline 4.7 & 4.0 & 74.3 & 53.5 & - & 0.085 & 3.9 & 4.0 & 89.6 & 72.4 & - & 0.105 & 5.0 \\
\hline 11.0 & 3.6 & 72.0 & 53.8 & - & 0.097 & 3.7 & 3.5 & 88.2 & 73.7 & - & 0.107 & 6.5 \\
\hline 17.3 & 3.3 & 72.7 & 57.6 & - & 0.112 & 3.0 & 3.3 & 78.1 & 68.0 & - & 0.089 & 10.9 \\
\hline 23.6 & 3.1 & 65.8 & 53.1 & 57.2 & 0.131 & 1.6 & 3.1 & 75.4 & 68.1 & 74.8 & 0.089 & 10.7 \\
\hline 29.8 & 3.0 & 52.8 & 42.4 & 47.5 & 0.153 & 1.6 & 3.0 & 70.0 & 58.9 & 67.7 & 0.088 & 10.8 \\
\hline 36.1 & 2.9 & 51.8 & 40.0 & 46.8 & 0.168 & 1.4 & - & - & - & - & - & - \\
\hline$P$ & & $* *$ & * & & $* *$ & * & & $* *$ & $* *$ & & * & * \\
\hline
\end{tabular}
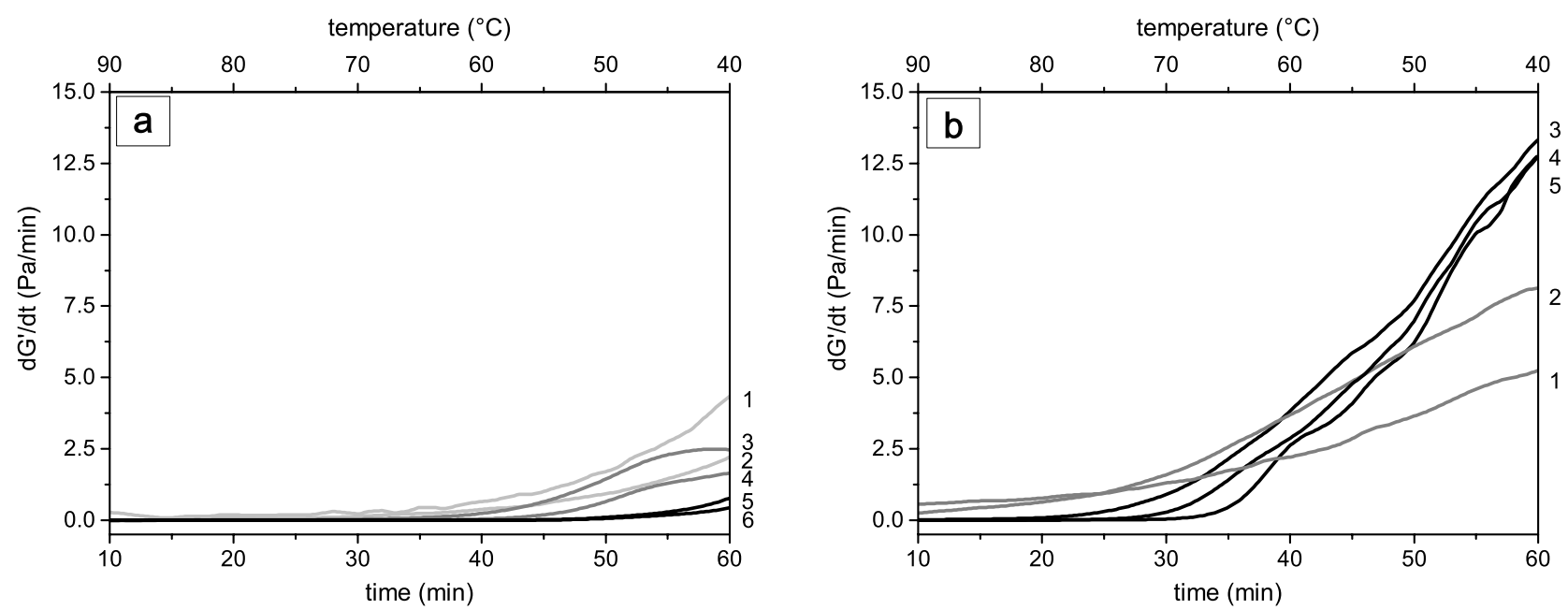

Fig. 2 Influence of the acid concentration of (a) LMP gels $(R=0.70)$ and (b) LMAP gels $(R=1.09)$ on the structuring velocity (dG'/dt); 1: $p H$ 4.0, 2: $p H 3.6$ (LMP) or 3.5 (LMAP), 3: $p H$ 3.3, 4: $p H$ 3.1, 5: $p H$ 3.0, 6: $p H$ 2.9.

The different level and shape of the structuring velocity curves of the LMP and LMAP gels (Fig. 2) confirm the differences in gelation behavior of the two pectin types. For LMP, the structuring velocity decreased with decreasing $\mathrm{pH}$. Obviously, the increasing number of hydrogen bonds between the non-dissociated carboxyl groups could not compensate the lack of calcium bridges. In case of LMAP, the steep increases of the curves (number 3 to 5 ) underline the supportive effect of the higher number of hydrogen bonds formed due to the presence of the amide groups. These groups considerably accelerated the gelling process and more than compensated the lack of ionic interactions at lower temperature. 
Comparing the SDR $\mathrm{a}_{\mathrm{a}}$ of the LMP and LMAP gelation, the differences were even more evident (Table 3). For LMP, values were rather low with a maximum at the highest $\mathrm{pH}$ of 4.0 . In contrast, in case of LMAP the $\mathrm{SDR}_{\mathrm{a}}$ at $\mathrm{pH} 4.0$ was at its minimum, but increased strongly down to $\mathrm{pH} 3.3$ and formed a plateau at lower $\mathrm{pH}$. Also the comparison of the final gel properties ( $\tan \delta_{\text {end) }}$ of the LMP and LMAP showed that the samples behaved differently with decreasing $\mathrm{pH}$ (Table 3). LMP gels became more viscous (liquid-like) and the gel structure was less compact. In contrast, LMAP gels became more elastic (solid-like) and the gel structure was in general more compact, independent from the $\mathrm{pH}$. These differences confirmed the impact of the decreasing number of calcium bridges and the positive effect of the hydrogen bonds as discussed above.

The presented results are in agreement with literature data. The pectin backbone, the polygalacturonate chain, may undergo a conformational transition with a shift in $\mathrm{pH}$. By lowering the temperature at $\mathrm{pH}$ below the $\mathrm{pK}_{\mathrm{a}}$, a more compact three-fold helix can be formed by minimizing electrostatic repulsion (Gilsenan, Richardson, \& Morris, 2000). Therefore, more carboxyl groups can act as donors in hydrogen bonds. Löfgren et al. (2006) also demonstrated that the $\mathrm{pH}$ affects the structuring process and gel properties of pectin. The microstructure of pectin gels at $\mathrm{pH} 3$ and $30 \%$ sucrose was open and highly aggregated, compared to gels formed at $\mathrm{pH} 7$ with a denser and more entangled structure. The authors stated that this difference resulted from a lower charge density and more compact conformational structure of the pectin molecules at $\mathrm{pH} 3$. For amidated pectin they reported, that the structure formation at $\mathrm{pH} 3$ was the highest of all tested gels and that the amide groups additionally strengthened the gel network by forming more hydrogen bonds.

Comparing the influence of $\mathrm{pH}$ on the gelation of LMP and LMAP with that on HMP (Kastner et al., 2014), a general decrease of the structuring temperatures with decreasing $\mathrm{pH}$ was found for all pectins. The effect was, however, much stronger for the two LMP samples. Once more, the gelling mechanisms were crucial for the understanding. Whereas in case of $\mathrm{HMP}$ a decreasing $\mathrm{pH}$ led to an increase in non-dissociated carboxyl groups and thus increased the chance for the formation of hydrogen bonds in the cold-set gelation, in case of LMP (and partly also the LMAP) it reduced the number of potential binding sites for calcium ions and, thus, inhibited the ionotropic gelation. Comparing the final gel properties ( $\tan \delta_{\text {end }}$ ), the effect of $\mathrm{pH}$ was strongest for LMP (strong increase) and lowest for LMAP (weak decrease). Obviously, the gelation of the LMAP was more affected by the formation of hydrogen bonds including the amide group, which seemed to be less $\mathrm{pH}$ dependent than those of the carboxyl groups. 


\subsection{Direct comparison of the structuring process of a LMP and a LMAP gelation}

Finally, a direct comparison of the structuring processes of a non-amidated and an amidated LMP, prepared with comparable calcium content ( 0.7 for the LMP and 0.73 for the LMAP) and under identical conditions of $\mathrm{pH}$ and cooling rate, might illustrate the principal differences between the structure formations of the two pectin types (Fig. 3, Table 4).

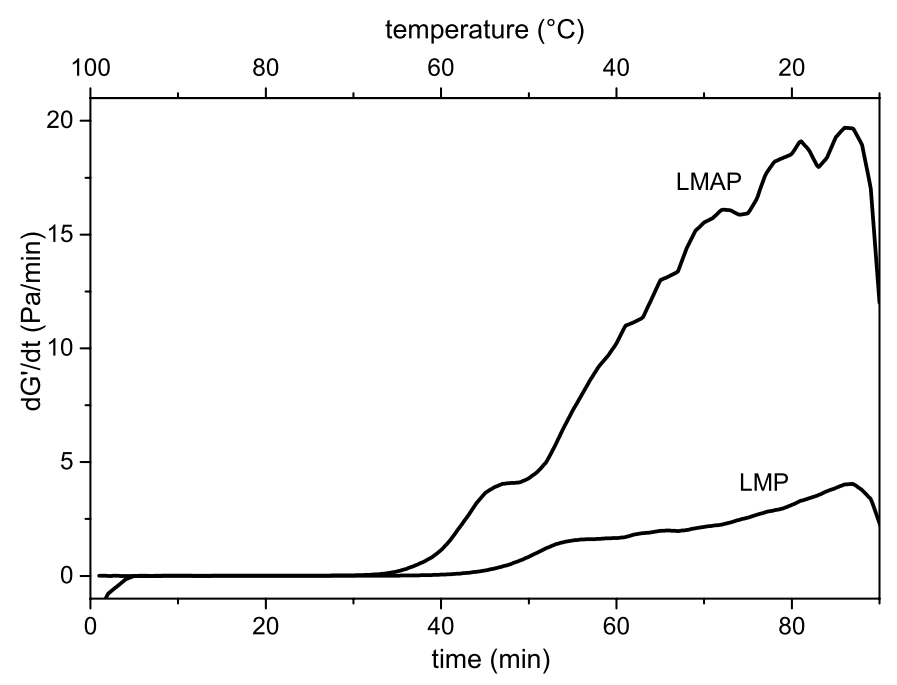

Fig. 3 Comparison of the structuring velocity curves (dG'/dt) of two LMP and LMAP gels with similar $R(0.70,0.73$, respectively) under the same conditions.

The structure formation velocities of non-amidated and amidated pectin differed significantly. The initial gelling process of LMP and LMAP was similar (comparable IST) but the real structure formation of the LMAP gel, as characterized by the GP temperature and the CST, started significantly earlier than that of LMP. Also the $\mathrm{SDR}_{\mathrm{a}}$ and the final gel structure (tan $\left.\delta_{\text {end }}\right)$ differed considerably. The SDR of the LMAP was more than five times as high as that of the LMP, the LMP gel was much more viscous ("soft") and the LMAP gels much more elastic (brittle).

Table 4 Comparison of LMP and LMAP gels with similar R. DM = degree of methoxylation, GC = galacturonan content, $D A=$ degree of amidation, $R=$ stoichiometric ratio of calcium ions, IST = initial structuring temperature, CST = critical structuring temperature, GP $=$ gel point, tan $\delta_{\text {end }}=$ loss factor as determined after the end of the gelation, $S D R_{a}=$ average structure developing rate. $\mathrm{P}$ indicates significant differences between LMP and LMAP: * for $\mathrm{P}<0.05,{ }^{* *}$ for $\mathrm{P}<0.01$ and ${ }^{* * *}$ for $\mathrm{P}<0.001$.

\begin{tabular}{|c|c|c|c|c|c|c|c|c|c|}
\hline & $\begin{array}{l}\text { DM } \\
(\%) \\
\end{array}$ & $\begin{array}{l}\text { GC } \\
(\%)\end{array}$ & $\begin{array}{l}\text { DA } \\
(\%)\end{array}$ & $\mathbf{R}$ & $\begin{array}{l}\text { IST } \\
\left({ }^{\circ} \mathrm{C}\right)\end{array}$ & $\begin{array}{l}\text { CST } \\
\left({ }^{\circ} \mathrm{C}\right) \\
\end{array}$ & $\begin{array}{l}\text { GP } \\
\left({ }^{\circ} \mathrm{C}\right)\end{array}$ & $\tan \delta_{e n d}$ & $\begin{array}{c}\mathrm{SDR}_{\mathrm{a}} \\
\text { (Pa/min) }\end{array}$ \\
\hline LMP & 30 & 82 & - & 0.70 & 65.8 & 53.1 & 57.2 & 0.131 & 1.6 \\
\hline LMAP & 32 & 68 & 19 & 0.73 & 65.8 & 60.3 & 64.4 & 0.079 & 10.5 \\
\hline
\end{tabular}

Thus, the direct comparison of the two gels clearly confirms the differences in the gelling mechanisms of non-amidated and amidated pectins as discussed above and, especially, the role of the amide group hydrogen bonds on the gelation of amidated LMP. 


\section{Conclusions}

The general aim of our work on structure formation of pectin gels was a detailed investigation of the influence of different parameters on the gelation kinetic of high-methoxylated, low-methoxylated and amidated pectins and on the different types of junction zones between pectin chains (hydrophobic interactions, hydrogen bonds and calcium-bridges).

As expected, the impact of the cooling conditions on LMP gels differed considerably from that on HMP gels. The formation of calcium bridges, which have a low sensitivity to temperature, reduced the effect of the cooling rate on LMP gelation. A delay of structure formation upon decrease of the pH was found for all types of pectin. In case of HMP (Kastner et al., 2014) it led to an increase in non-dissociated carboxyl groups and, thus, increased the chance for the formation of hydrogen bonds. For LMP and partly also LMAP, a decrease of $\mathrm{pH}$ reduced the number of potential binding sites for calcium ions and, thus, inhibited the gelation. Moreover, the gelation of LMAP was considerably influenced by the formation of hydrogen bonds including the amide group, which seemed to be less dependent on $\mathrm{pH}$ than hydrogen bonds between the carboxyl groups. Comparing a non-amidated and an amidated LMP, differences in the structure formation were also found with respect to the calcium concentration. On the one hand, fast saturation of the low number of dissociated free carboxyl groups in LMAP with calcium ions may result in a reduced number of ionic interactions. On the other hand, the formation of hydrogen bonds involving the amide groups in LMAP may considerably promote the structuring process. A LMAP gel seemed to be more 'stable' than a non-amidated LMP gel prepared at the same calcium ratio $\mathrm{R}$.

In summary, the results presented confirm the assumptions on the differences in HMP, LMP and LMAP gelation and proof the principal differences in the structure formation of pectin with varying DM in dependence on the gelling conditions. This knowledge is essential because pectin is prepared from biological raw materials with varying structure and, thus, properties. Pectin suppliers adjust their products to specific requirements by adapting the method of extraction and subsequent modification. The type of demethoxylation of the commercial LMP applied in the presented work was not defined in detail. We assume, however, that also the type of the pectin demethoxylation (acidic, enzymatic) may have a certain effect on the gelling process of pectin. Therefore, the impact of different pectin demethoxylation methods on the structuring process will be the subject of our further work.

\section{Acknowledgments}

The authors would like to thank Karla Kern for the skillful technical assistance during the pectin gel preparation. 


\section{References}

Alonso-Mougán, M., Meijide, F., Jover, A., Rodríguez-Núñez, E., \& Vázquez-Tato, J. (2002).

Rheological behaviour of an amide pectin. Journal of Food Engineering, 55(2), 123-129.

https://doi.org/10.1016/S0260-8774(02)00026-2

Axelos, M. A. V., \& Kolb, M. (1990). Crosslinked biopolymers: Experimental evidence for scalar percolation theory. Physical Review Letters, 64(12), 1457-1460.

https://doi.org/10.1103/PhysRevLett.64.1457

Black, S. A., \& Smit, C. J. B. (1972). The effect of demethylation procedures on the quality of lowester pectins used in dessert gels. Journal of Food Science, 37(5), 730-732.

https://doi.org/10.1111/j.1365-2621.1972.tb02737.x

Braccini, I., \& Pérez, S. (2001). Molecular basis of Ca2+-induced gelation in alginates and pectins: the egg-box model revisited. Biomacromolecules, 2(4), 1089-1096.

https://doi.org/10.1021/bm010008g

Burey, P., Bhandari, B. R., Howes, T., \& Gidley, M. J. (2008). Hydrocolloid Gel Particles: Formation, Characterization, and Application. Critical Reviews in Food Science and Nutrition, 48(5), 361-377. https://doi.org/10.1080/10408390701347801

Capel, F., Nicolai, T., Durand, D., Boulenguer, P., \& Langendorff, V. (2006). Calcium and acid induced gelation of (amidated) low methoxyl pectin. Food Hydrocolloids, 20(6), 901-907. https://doi.org/10.1016/j.foodhyd.2005.09.004

Cárdenas, A., Goycoolea, F. M., \& Rinaudo, M. (2008). On the gelling behaviour of "nopal" (Opuntia ficus indica) low methoxyl pectin. Carbohydrate Polymers, 73(2), 212-222.

https://doi.org/10.1016/j.carbpol.2007.11.017

Einhorn-Stoll, U., Kastner, H., \& Drusch, S. (2014). Thermally induced degradation of citrus pectins during storage - Alterations in molecular structure, colour and thermal analysis. Food Hydrocolloids, 35, 565-575. https://doi.org/10.1016/j.foodhyd.2013.07.020

Einhorn-Stoll, U., Kastner, H., Hecht, T., Zimathies, A., \& Drusch, S. (2015). Modification and physico-chemical properties of citrus pectin - Influence of enzymatic and acidic demethoxylation. Food Hydrocolloids, 51, 338-345. https://doi.org/10.1016/j.foodhyd.2015.05.031

Einhorn-Stoll, U., Kastner, H., \& Senge, B. (2012). Comparison of Molecular Parameters; Material Properties and Gelling behaviour of Commercial Citrus Pectins. In P. A. Williams \& G. O. Phillips (Eds.), Gums and Stabilisers for the Food Industry 16 (pp. 199-206). Retrieved from https://doi.org/10.1039/9781849734554-00199 
Einhorn-Stoll, U., Prinz, C., \& Drusch, S. (2014). Influence of Storage on the Water Binding of Pectin: Determination by DSC. In P. A. Williams \& G. O. Phillips (Eds.), Gums and Stabilisers for the Food Industry 17 : The Changing Face of Food Manufacture: The Role of Hydrocolloids (pp. 147-154). Retrieved from https://doi.org/10.1039/9781782621300-00147

Endress, H. U., \& Christensen, S. H. (2009). Pectins. In G. O. Phillips \& P. A. Williams (Eds.), Handbook of Hydrocolloids (2nd ed., pp. 274-297). Cambridge: Woodhead Publishing. Retrieved from http://www.sciencedirect.com/science/article/pii/B9781845694142500126

Evageliou, V., Richardson, R. K., \& Morris, E. R. (2000). Effect of pH, sugar type and thermal annealing on high-methoxy pectin gels. Carbohydrate Polymers, 42(3), 245-259.

https://doi.org/10.1016/S0144-8617(99)00191-5

Fang, Y., Al-Assaf, S., Phillips, G. O., Nishinari, K., Funami, T., \& Williams, P. A. (2008). Binding behavior of calcium to polyuronates: Comparison of pectin with alginate. Carbohydrate Polymers, 72(2), 334-341. https://doi.org/10.1016/j.carbpol.2007.08.021

Fraeye, I., Colle, I., Vandevenne, E., Duvetter, T., Van Buggenhout, S., Moldenaers, P., ... Hendrickx, M. (2010). Influence of pectin structure on texture of pectin-calcium gels. Innovative Food Science \& Emerging Technologies, 11(2), 401-409. https://doi.org/10.1016/j.ifset.2009.08.015

Fraeye, I., Doungla, E., Duvetter, T., Moldenaers, P., Van Loey, A., \& Hendrickx, M. (2009). Influence of intrinsic and extrinsic factors on rheology of pectin-calcium gels. Food Hydrocolloids, 23(8), 2069-2077. https://doi.org/10.1016/j.foodhyd.2009.03.022

Garnier, C., Axelos, M. A. V., \& Thibault, J.-F. (1993). Phase diagrams of pectin-calcium systems: Influence of $\mathrm{pH}$, ionic strength, and temperature on the gelation of pectins with different degrees of methylation. Carbohydrate Research, 240, 219-232. https://doi.org/10.1016/0008-6215(93)84185-9

Garrido, J. I., Lozano, J. E., \& Genovese, D. B. (2015). Effect of formulation variables on rheology, texture, colour, and acceptability of apple jelly: Modelling and optimization. LWT - Food Science and Technology, 62(1, Part 1), 325-332. https://doi.org/10.1016/j.Iwt.2014.07.010

Gigli, J., Garnier, C., \& Piazza, L. (2009). Rheological behaviour of low-methoxyl pectin gels over an extended frequency window. Food Hydrocolloids, 23(5), 1406-1412.

https://doi.org/10.1016/j.foodhyd.2008.09.015

Gilsenan, P. M., Richardson, R. K., \& Morris, E. R. (2000). Thermally reversible acid-induced gelation of low-methoxy pectin. Carbohydrate Polymers, 41(4), 339-349.

https://doi.org/10.1016/S0144-8617(99)00119-8

Grosso, C. R. F., \& Rao, M. A. (1998). Dynamic rheology of structure development in low-methoxyl 
pectin Ca2+ sugar gels. Food Hydrocolloids, 12(3), 357-363. https://doi.org/10.1016/S0268005X(98)00034-4

Guillotin, S. E., Van Kampen, J., Boulenguer, P., Schols, H. A., \& Voragen, A. G. J. (2006). Degree of blockiness of amide groups as indicator for difference in physical behavior of amidated pectins. Biopolymers, 82(1), 29-37. https://doi.org/10.1002/bip.20456

Holst, P. S., Kjøniksen, A.-L., Bu, H., Sande, S. A., \& Nyström, B. (2006). Rheological properties of pH-induced association and gelation of pectin. Polymer Bulletin, 56(2-3), 239-246.

https://doi.org/10.1007/s00289-005-0489-8

Iglesias, M. T., \& Lozano, J. E. (2004). Extraction and characterization of sunflower pectin. Journal of Food Engineering, 62(3), 215-223. https://doi.org/10.1016/S0260-8774(03)00234-6

Kastner, H., Einhorn-Stoll, U., \& Senge, B. (2012a). New parameters for the examination of the pectin gelation process. In P. A. Williams \& G. O. Phillips (Eds.), Gums and Stabilisers for the Food Industry 16 (pp. 191-197). Retrieved from https://doi.org/10.1039/9781849734554-00191

Kastner, H., Einhorn-Stoll, U., \& Senge, B. (2012b). Structure formation in sugar containing pectin gels - Influence of $\mathrm{Ca} 2+$ on the gelation of low-methoxylated pectin at acidic $\mathrm{pH}$. Food Hydrocolloids, 27(1), 42-49. https://doi.org/10.1016/j.foodhyd.2011.09.001

Kastner, H., Kern, K., Wilde, R., Berthold, A., Einhorn-Stoll, U., \& Drusch, S. (2014). Structure formation in sugar containing pectin gels - Influence of tartaric acid content $(\mathrm{pH})$ and cooling rate on the gelation of high-methoxylated pectin. Food Chemistry, 144, 44-49.

https://doi.org/10.1016/j.foodchem.2013.06.127

Liners, F., Thibault, J.-F., \& Cutsem, P. V. (1992). Influence of the degree of polymerization of oligogalacturonates and of esterification pattern of pectin on their recognition by monoclonal antibodies. Plant Physiology, 99, 1099-1104. https://doi.org/10.1104/pp.99.3.1099

Löfgren, C., Guillotin, S., \& Hermansson, A.-M. (2006). Microstructure and kinetic rheological behavior of amidated and nonamidated LM pectin gels. Biomacromolecules, 7(1), 114-121. https://doi.org/10.1021/bm050459r

Löfgren, C., \& Hermansson, A.-M. (2007). Synergistic rheological behaviour of mixed HM/LM pectin gels. Food Hydrocolloids, 21(3), 480-486. https://doi.org/10.1016/j.foodhyd.2006.07.005

Lootens, D., Capel, F., Durand, D., Nicolai, T., Boulenguer, P., \& Langendorff, V. (2003). Influence of $\mathrm{pH}$, Ca concentration, temperature and amidation on the gelation of low methoxyl pectin. Food Hydrocolloids, 17(3), 237-244. https://doi.org/10.1016/S0268-005X(02)00056-5

Lopes da Silva, J. A., \& Gonçalves, M. P. (1994). Rheological study into the ageing process of high 
methoxyl pectin/sucrose aqueous gels. Carbohydrate Polymers, 24(4), 235-245.

https://doi.org/10.1016/0144-8617(94)90068-X

Luzio, G. A., \& Cameron, R. G. (2008). Demethylation of a model homogalacturonan with the saltindependent pectin methylesterase from citrus: Part II. Structure-function analysis. Carbohydrate Polymers, 71(2), 300-309. https://doi.org/10.1016/j.carbpol.2007.05.038

Ngouémazong, D. E., Tengweh, F. F., Fraeye, I., Duvetter, T., Cardinaels, R., Van Loey, A., ... Hendrickx, M. (2012). Effect of de-methylesterification on network development and nature of Ca2+pectin gels: Towards understanding structure-function relations of pectin. Food Hydrocolloids, 26(1), 89-98. https://doi.org/10.1016/j.foodhyd.2011.04.002

Oakenfull, D., \& Fenwick, D. E. (1977). Thermodynamics and mechanism of hydrophobic interaction. Australian Journal of Chemistry, 30(4), 741-752. https://doi.org/10.1071/CH9770741

Oakenfull, D., \& Scott, A. (1984). Hydrophobic interaction in the gelation of high methoxyl pectins. Journal of Food Science, 49(4), 1093-1098. https://doi.org/10.1111/j.1365-2621.1984.tb10401.x

Powell, D. A., Morris, E. R., Gidley, M. J., \& Rees, D. A. (1982). Conformations and interactions of pectins: II. Influence of residue sequence on chain association in calcium pectate gels. Journal of Molecular Biology, 155(4), 517-531. https://doi.org/10.1016/0022-2836(82)90485-5

Ralet, M.-C., Dronnet, V., Buchholt, H. C., \& Thibault, J.-F. (2001). Enzymatically and chemically de-esterified lime pectins: characterisation, polyelectrolyte behaviour and calcium binding properties. Carbohydrate Research, 336(2), 117-125. https://doi.org/10.1016/S00086215(01)00248-8

Rao, M. A., \& Cooley, H. J. (1993). Dynamic rheological measurement of structure development in high-methoxyl pectin/fructose gels. Journal of Food Science, 58(4), 876-879.

https://doi.org/10.1111/j.1365-2621.1993.tb09381.x

Rolin, C., Chrestensen, I. B., Hansen, K. M., Staunstrup, J., \& Sørensen, S. (2009). Tailoring pectin with specific shape, composition and esterification pattern. In P. A. Williams \& G. O. Phillips (Eds.), Gums and Stabilisers for the Food Industry 15 (pp. 13-25). Cambridge: Royal Society of Chemistry. Retrieved from http://dx.doi.org/10.1039/9781849730747-00013

Siew, C. K., Williams, P. A., \& Young, N. W. G. (2005). New insights into the mechanism of gelation of alginate and pectin: Charge annihilation and reversal mechanism. Biomacromolecules, 6(2), 963969. https://doi.org/10.1021/bm049341/

Sousa, A. G., Nielsen, H. L., Armagan, I., Larsen, J., \& Sørensen, S. O. (2015). The impact of rhamnogalacturonan-I side chain monosaccharides on the rheological properties of citrus pectin. 
Food Hydrocolloids, 47, 130-139. https://doi.org/10.1016/j.foodhyd.2015.01.013

Ström, A., Ribelles, P., Lundin, L., Norton, I., Morris, E. R., \& Williams, M. A. K. (2007). Influence of pectin fine structure on the mechanical properties of calcium-pectin and acid-pectin gels.

Biomacromolecules, 8(9), 2668-2674. https://doi.org/10.1021/bm070192r

Ström, A., \& Williams, M. A. K. (2003). Controlled Calcium Release in the Absence and Presence of an Ion-Binding Polymer. The Journal of Physical Chemistry B, 107(40), 10995-10999.

https://doi.org/10.1021/jp034322b

Thakur, B. R., Singh, R. K., Handa, A. K., \& Rao, D. M. A. (1997). Chemistry and uses of pectin A review. Critical Reviews in Food Science and Nutrition, 37(1), 47-73.

https://doi.org/10.1080/10408399709527767

Thibault, J.-F., \& Ralet, M.-C. (2003). Physico-chemical properties of pectins in the cell walls and after extraction. In F. Voragen, H. Schols, \& R. Visser (Eds.), Advances in Pectin and Pectinase Research (pp. 91-105). Springer Netherlands. Retrieved from http://dx.doi.org/10.1007/978-94-017$0331-4 \_7$

Tsoga, A., Richardson, R. K., \& Morris, E. R. (2004). Role of cosolutes in gelation of high-methoxy pectin. Part 1. Comparison of sugars and polyols. Food Hydrocolloids, 18(6), 907-919. https://doi.org/10.1016/j.foodhyd.2004.03.001

Vincent, R. R., \& Williams, M. A. K. (2009). Microrheological investigations give insights into the microstructure and functionality of pectin gels. Carbohydrate Research, 344(14), 1863-1871. https://doi.org/10.1016/j.carres.2008.11.021

Walstra, P. (2002). Physical Chemistry of Foods. New York: Taylor \& Francis Inc.

Wang, K., Hua, X., Yang, R., Kang, J., \& Zhang, W. (2014). Hydrodynamic behavior and gelling properties of sunflower head pectin in the presence of sodium salts. Food Hydrocolloids, 36, 238244. https://doi.org/10.1016/j.foodhyd.2013.09.011

Yapo, B. M., \& Gnakri, D. (2015). Pectic polysaccharides and their functional properties. In K. G. Ramawat \& J.-M. Mérillon (Eds.), Polysaccharides - Bioactivity and Biotechnology (pp. 1729-1746). Springer International Publishing.

Ziegler, G. R., \& Foegeding, E. A. (1990). The gelation of proteins. In J. E. Kinsella (Ed.), Advances in Food and Nutrition Research (Vol. 34, pp. 203-298). Academic Press. 